\title{
COMMUNICATION MIGHT BOOST THE EUROPEAN CULTURAL CAPITAL PROGRAM - CASE STUDY SIBIU 2007
}

\author{
Rotariu Ilie, senior lecturer, ilie.rotariu@ulbsibiu.ro \\ "Lucian Blaga” University of Sibiu
}

\begin{abstract}
This paper is a case study: the town of Sibiu - Transylvania - Romania. There is no doubt that Sibiu area has already gathered the critical mass of its development capable to satisfy the requests of the tourists in order to be considered as a tourist destination according to Gunn' criterion. A good communication is compulsory to boost a tourist destination for the both major actors: the organizers and the population - the potential tourists. We argue that the destination has started to communicate with the world and is learning how to improve its capabilities of dialogue. But the world has also begun to communicate with Sibiu, and at the end of the line with Romania, after knowing what it is and who its inhabitants are. And more important, the natives started to talk one another according the nowadays global custom. The European Cultural Capital has boosted the communication of a new discovered tourist destination according to the current global routine.
\end{abstract}

This paper was intended to be a case study: the town of Sibiu - Transylvania - Romania as the European Cultural Capital 2007 with Luxembourg. I've planed to investigate the second of the most significant events my town, and its citizens has experienced the last decades (for the other one I cote the Romanian Revolution - December '89, when Sibiu has experienced the bloodiest and the strangest days during the last century). My field researches have shown that "Boosting the Communication of a Tourist Destination by the European Cultural Capital Program" is a topic with too large connections, associations and implications. I was therefore obliged to stay on an outline and to carry on my work by further investigations. As a consequence this paper has to be an invitation to join the researches for anyone which can contribute to clear the problems or answer the questions that will arise.

The program The European Cultural Capital is one of the success stories of EU. My first purpose was the "boule de neige"'s effect among the towns of Romania and the neighbouring countries. The evidence has proven once again that common people of EU have hardly heard about Sibiu before this program. Usually Bucharest is taken for Budapest. I have to enlarge my quest.

There is no doubt that Sibiu area has already gathered the critical mass of its development capable to satisfy the requests of the tourists in order to be considered as a tourist destination according to usual criteria.

I have found out that the destination has started to communicate: the natives started to talk one another, with the world, with Romania. The European Cultural Capital has boosted the communication of a new discovered tourist destination according to the current global routine.

This paper, this outline is destined for my foreign audience but also for my co citizen that might add, complete and conclude the topic (I hope so!). I am obliged to highlight some points that are usual unknown or ignored by EU people as well as by the Romanians that might have a different perceptions of the facts as they are usually used in Western developed countries. 
50 years of Cold War and a decade of total isolation of Romania might have put their imprint and still might influence the common understandings.

Designed to "contribute to bringing the peoples of Europe together", the European City of Culture project was launched, at the initiative of Melina Mercouri, by the Council of Ministers on 13 June 1985. It has become ever more popular with the citizens of Europe and has seen its cultural and socio-economic influence grow through the many visitors it has attracted. The European Cities of Culture have been chosen until 2004, on an intergovernmental basis; the Member States unanimously selected cities worthy of hosting the event, and the European Commission awarded a grant each year to the city selected.

For the time being, the European Capitals of Culture are designated each year by the Council of Ministers of the EU, on the basis of the view of a selection panel comprising seven prominent independent members, each of them experts in the culture sector. The selection procedure is laid down in Decision 1419/1999/CE amended by Decision 649/2005/CE. This Decision sets out a chronological list of Member States entitling them to host the event in turn. It defines as well the criteria the cities have to comply with to be designated as European Capital of Culture.

There have been 31 Cities of Culture to date (2004 NN). Nine cities shared the title in 2000 and for 2001, 2002 and 2004 two cities were designed to share the title.

Since the publication of the 1994 study on European Cities of Culture and Cultural Months, reports of the event have been compiled only on the initiative of individual cities themselves. Such reports are inconsistent, and many remain unpublished. It is therefore timely and useful that the European Commission commissioned a study on the European Cities and Capitals of Culture to Palmer/Rae Associates, Brussels that were use as a good information source in Sibiu too. The objectives of the study were as follows:

1. To document past European Cities and Capitals of Culture, focusing in particular on the following aspects:

i. Organisation of the event (structures, responsibilities, staffing)

ii. Financing (public funding, sponsoring, other sources)

iii. Cultural impacts, to include:

a. Content and organisation of the cultural programme

b. European dimension

c. Effects on the cultural life of the city, surrounding region and country (if relevant)

iv. Economic Impacts

v. Visitor/Tourism Impacts

vi. Social Impacts

simultaneously

vii. Cooperation between cities when two or more cities organised the event

viii. Other issues as appropriate

- To make observations on the effects of variations between cities, in relation to aspects listed above

- To offer a factual analysis of the Capital of Culture events based on documented information

2. The study presents findings in a manner to be of value to the European Commission as well as other EU institutions, to future cities when undertaking preparations for the Capital of Culture event, and to researchers, journalists and others interested in European Capitals of Culture and related topics.

3. The study also offers a basis for future policy-making in the field. 
I have tried to approach as much as possible the same structure. Any time when my findings were incomplete or methodological insufficient I have pointed out that further researches must follow.

Quoting the organizers:

"Sibiu 2007 represents a once-in-a-generation opportunity for a Romanian city to host the European Capital of Culture designation.

Sibiu/Hermannstadt as European Capital of Culture in 2007 aims at opening gates through which the city's rich cultural landscape and diverse life will meet that of Europe. The Ministries of Culture from Luxembourg and Romania agreed in 2000 to cooperate in the cultural field and the cooperation engagement was renewed in 2002 and 2004 and enriched with the agreement of sharing the role of European Capital of Culture in 2007.

This that the partnership between Luxembourg and Sibiu/Hermannstadt has a profound basis not only in the history but also in the present.

The theme chosen by Sibiu/Hermannstadt - "City of Culture-City of Cultures" - matches very well the ones of Luxembourg - "Europe of the Future" and "Discovering Yourself Discovering Others".

As well as recognising the city's existing cultural excellence, 'Sibiu European Capital of Culture 2007' is designed to encourage the City of Sibiu to develop and innovate through cultural action.

The Programme is designed to promote cultural cooperation and to celebrate the European destiny of Sibiu, through a cultural programme with European dimension and significance.

'Sibiu European Capital of Culture 2007' will offer opportunities for social inclusion and cohesion, business, education, tourism, heritage and urban regeneration at every level. The Programme puts culture at the heart of city life and seeks inspiration to drive it forward.

After few rounds of public meetings and debates, the representatives of the local actors decided to form an NGO which will be entrusted with the organization of Sibiu/Hermannstadt 2007.

The Juridical Department of the Municipality undertook the first steps towards establishing a non-lucrative association named "Association Sibiu/Hermannstadt European Capital of Culture 2007" and registering it in a court of law according to Romanian laws. The operations of the Association will be internally and externally audited. The Management Board of the Association Sibiu/Hermannstadt European Capital of Culture 2007 is entitled to take the decisions regarding the organization of the European Capital of Culture Sibiu/Hermannstadt 2007.

The budget at the disposal of the Sibiu 2007 Association has been put in place so far by Sibiu Town Hall and Romanian Government.

Before going on, we have to answer a question: Why they have chosen Sibiu?

This is a pertinent question and the answer might relieve the way of thinking of those implied into this decision, which were the strong points, than the weak ones and more, the conclusions might serve for further applications. An appeal for projects for 2007 - 2013 is already opened at http://ec.europa.eu/culture/eac/index_en.html, and for this period finance is crucial to continue the program. Theoretically, it might not be a problem to draw a list with a couple of dozens of officials from EU and send them a questionnaire. It takes time, as information is split among people involved, and soon, after the end of the program, will be practical impossible to find it. There is still time to write the list, to have the addresses for the evaluation! 
There are some reasons usually admitted:

- Sibiu was the second town, the first was Luxembourg. Luxembourg was a European Cultural Capital in 1995 too. As the first on the list, its choice was imposed. Why Luxembourg has chosen Sibiu. There are some reasons: "after", when people from Luxembourg came with aids, they have spoken using their dialect with locals of a neighbourhood of Sibiu, whose ancestors, some centuries ago come as colonists. A sort of "refinding the lost brother"! And the story has started...

- the story has multiplied with Deventer (Holland) and the surroundings, with Vienna, Germany etc. That might brought sympathy and support when decided the second town and the winners.

- after ' 89 there were a lot of contacts with EU. People of Sibiu, travelling or settled in EU, (quite different of the Gipsies that were Romania's image at the time). People of EU countries on official, unofficial or private visits in Sibiu, where they have found normal citizen, with an interesting and similar life. The German Consulate might play the role of a guarantee.

- Sibiu enjoyed a long tradition and organized plenty of events - Jazz Festival, Folk Festival, Pottery Fear, Theatre Festival, Film Festival etc. etc. and had a usual tourism. Many traditions similar with what visitors are used too.

- I add also an important element: the foreign visitors have found a society much similar to their; we have to bear in mind that the Western Europeans or the Americans of European origin do not use to change their behaviours: they have imposed all over the world their values and the societies that come in touch with them had to change accordingly. Otherwise they fail to be treated as savages, as former "barbarians". Starting January 1990 the civil society has grown fast in Sibiu. Associations and organisations, independent and almost private have practically exploded. The two main churches: Orthodox and specially Evangelic have come back to their role. Meantime, in Romania the state system was still powerful. Visitors of EU have found in Sibiu, beside their history and roots, also the same society that made them feel like home and turned them as being a part. Add the medieval environment, the habitude of local people, and their use to host. And you might find the reason way, in a Balkan country, in Transylvania they have found something of their immemorial spirit.

- We have not to forget that for EU a program is a tool of management, finally a business. Palmer Report has pointed out significant information that has opened my mind and has given me the idea of this research. EU European Cultural Capital Program is a performing one. EU just put a drop $(\mathbf{1 . 1 9 \%}=\mathbf{E U}$ founding) and get the splendour of a "tempest" $(\mathbf{9 8 . 8 1 \%}=$ Total income $)$. When the selection of candidates was done, the Eastern wave was ready to join EU and for 2007 the first two Orthodox countries were expected to follow. A successful example was well come. And looking around, in Romania and in Bulgaria too, Sibiu enjoys a unique position as I have shown before. And Luxembourg was the main town, ready to share its experience, acquired during its first nomination.

I am supposed to prove all these. Methodologically, it is theoretical possible, but practical is too costly. My considerations might be real: further researches might validate them, if they will be taken into consideration. Researches have already started to investigate and valorise the program for long time, as 2007 events will have an end and without a data base that might be used in future no one will remember it.

As far as we are, the European Cultural Capital Program Sibiu 2007 is a success and has the opportunity to be closed well.

The "boule de neige" effect is large and Sibiu has take advantage of it to get a new face. Large investments have completely changed not only the facilities for culture but the whole town. 
Sibiu has a good image and starts to be known. Romania has also improved its image through this program. The process must be continued to keep what was won and go further.

The communication was improved inside the town as well as with people of Romania or foreigners mainly by mass media and tourists.

Sibiu has all necessary elements to be a tourist destination. It felts the knowledge and the unity of tourism operators to be sold as a brand. It still has to wait to valorise its whole potential because of lake of infrastructure in the country, especially for transportation that cut its connections.

Organized and methodological researches in the field of tourism are compulsory and urgent.

\section{Bibliography:}

1. Lakatos, I - The methodology of scientific research programmes Cambridge University Press, 1995

2. PALMER/RAE ASSOCIATES - European Cities and Capitals of Culture, Study Prepared for the European Commission, 2004, pag 16

3. Greg Richards and Erik Hitters - Rotterdam Cultural Capital 2001: visitor research, ATLAS 2001

4. Gunn, C. A. (1994). Tourism Planning: Basics, Concepts and Cases, 3rd ed, Taylor and Francis, New York.

www.sibiu2007.ro 